\author{
ACTA MYCOLOGICA \\ Vol. 44 (1): 7-9 \\ 2009
}

\title{
European record of Subramaniula thielavioides on opium poppy
}

\author{
MARTIN PASTIRČÁK ${ }^{1}$ and KATARÍNA PASTIRČÁKOVÁ \\ ${ }^{1}$ Slovak Agricultural Research Centre, Research Institute of Plant Production \\ Bratislavská cesta 122, SK-92168 Piešt’any, uefemapa@hotmail.com \\ ${ }^{2}$ Slovak Academy of Sciences, Institute of Forest Ecology, Branch of Woody Plants Biology \\ Akademická 2, SK-94901 Nitra, uefezima@hotmail.com
}

Pastirčák M., Pastirčáková K.: European record of Subramaniula thielavioides on opium poppy. Acta Mycol. 44 (1): 7-9, 2009.

In the course of a study of fungal biodiversity of opium poppy (Papaver somniferum) plants collected in production area of Slovakia, an ascomycete belonging to the genus Subramaniula was isolated. The fungus identified as Subramaniula thielavioides has been reported for the first time from Slovakia. This record also represents the first European locality. Brief morphological description of the fungus based on an isolate from flower petals of opium poppy is provided.

Key words: Subramaniula thielavioides, Sordariales, Papaver somniferum, Slovakia

\section{INTRODUCTION}

The genus Subramaniula Arx (Chaetomiaceae, Sordariales) includes two species, Subramaniula irregularis P.F. Cannon \& D. Hawksw. and S. thielavioides (Arx, Mukerji \& N. Singh) Arx designated as the type species. Morphologically, Subramaniula thielavioides differs from $S$. irregularis by much smaller ascospores and irregularly shaped but usually lacrimiform or obovate ascospores. According to Arx (1985), morphological features of Subramaniula thielavioides show affinities to some species of Thielavia Zopf, Chaetomium Kunze and Podospora Ces. The genus Subramaniula differs from these genera by urniform, pale ascomata with a very wide apical ostiole surrounded by a ring of hyaline cells. Arx et al. (1978) observed non-ostiolate ascomata occasionally. An anamorphic connection is unknown. Only Cannon (1986) observed a few hyphae with chains of considerably swollen cells, producing thinwalled globose or ellipsoidal bodies, probably related to the anamorph.

During survey of fungal mycobiota of opium poppy (Papaver somniferum L.) the ascomycete $S$. thielavioides was isolated. Subramaniula thielavioides is not included 
in the checklist of fungi of Slovakia (Lizoň, Bacigálová 1998). There are no published data on the biology and natural occurrence of this ascomycete in Slovakia and no species of Subramaniula have been recorded in the country so far. The species $S$. thielavioides is newly described for Slovakia.

\section{MATERIAL AND METHODS}

Flower petals of opium poppy were collected at locality Dvory nad Žitavou (western Slovakia) in June 2006. Fresh material was surface-sterilized by immersion in $80 \%$ alcohol for $1 \mathrm{~min}$ and 5\% commercial bleach solution of sodium hypochlorite SAVO (Bochemie, Bohumín, Czech Republic) for $1 \mathrm{~min}$ and plated on SNA agar (Leslie, Summerell 2006) in $90 \mathrm{~mm}$ Petri dishes. Petri plates were incubated at $22^{\circ} \mathrm{C}$. The morphological features of the fungus sporulating in pure culture were examined by means of standard light microscopy (Jenamed2, Carl Zeiss Jena, Germany). Slide preparations were stained with lactophenol blue solution (Merck, Darmstadt, Germany). The morphological structures (ascocarps, asci and ascospores) were photographically documented by digital camera Olympus CAMEDIA C-4000 ZOOM. Representative material has been deposited in the Mycological Herbarium of Research Institute of Plant Production in Piešt'any, Slovakia.

\section{TAXONOMIC DESCRIPTION}

Subramaniula thielavioides (Arx, Mukerji \& N. Singh) Arx, Proc. Indian Acad. Sci., Pl. Sci. 94 (2-3): 344 (1985).

Basionym: Achaetomium thielavioides Arx, Mukerji \& N. Singh, Persoonia 10 (1): 144 (1978).

The following description is based on a fresh isolate from flower petals of opium poppy. Colonies on SNA agar with hyaline submerged mycelium; aerial mycelium scanty and hyaline; ascomata (perithecia) started appearing on the 10th day of incubation, scattered over or below (into) the agar surface. Ascomata globose, 160-460 $\mu \mathrm{m}$ in diam., without short neck, the collar of thin-walled hyaline cells around the ostiole. Ascomatal hairs absent; narrow hyaline hyphae emanating from various points on the ascoma surface. Periphyses not seen. Asci clavate, short-stalked, very thin-walled, without apical structures, evanescent at a very early stage, 8-spored, 75-96 $\times 10.5-18 \mu \mathrm{m}$. Ascospores widely fusiform, brownish, relatively thick-walled, 20.5-34 $\times 11.5-19 \mu \mathrm{m}, 1$-celled, with a conspicuous subapical germ pore up to $3.5 \mu \mathrm{m}$ wide (Fig. 1). Anamorph not seen.

SPECIMEN EXAMINED. Slovakia, Dvory nad Žitavou, opium poppy field, 47.9937 N, 18.2678 E, living flower petals of Papaver somniferum, 23 Jun 2006, leg. M. Pastirčák. 
Biometric data of ascomata and asci containing ascospores in general correspond to those given by Arx et al. (1978), Arx (1985), and Cannon (1986). The measurements of ascomata, asci and ascospores of the Slovak specimen compared with those recorded by previous authors are given in Table 1 . On the basis of morphological description and measurements of reproductive structures, the fungus was identified as Subramaniula thielavioides.

Table 1

Subramaniula thielavioides: measurements of ascomata, asci and ascospores compared with previous descriptions

\begin{tabular}{|l|c|c|c|}
\hline \multicolumn{1}{|c|}{ Source of data } & $\begin{array}{c}\text { Ascomata } \\
(\text { in diam., } \mu \mathrm{m})\end{array}$ & $\begin{array}{c}\text { Asci size } \\
(\mu \mathrm{m})\end{array}$ & $\begin{array}{c}\text { Ascospores size } \\
(\mu \mathrm{m})\end{array}$ \\
\hline Present study (average $\pm \mathrm{sd})$ & $330 \pm 92$ & $85 \pm 7.5 \times 13 \pm 2.5$ & $26 \pm 3 \times 14.5 \pm 1.5$ \\
\hline Range (min-max) & $160-460$ & $75-96 \times 10.5-18$ & $20.5-34 \times 11.5-19$ \\
\hline Arx et al. (1978) & $150-240$ & $50-78 \times 18-35$ & $21-27 \times 13-16$ \\
\hline Arx (1985) & $130-200$ & - & $23-27 \times 13-17$ \\
\hline Cannon (1986) & $130-200 \times 110-160$ & $45-69 \times 18-31$ & $22-26 \times 11.5-14.5$ \\
\hline
\end{tabular}

According to Cannon (1986), Subramaniula thielavioides is almost certainly no pathogen. Although Arx et al. (1978) includes this species in coprophilous fungi; the fungus was isolated from human nails, vertebrate dung, and soil. Until recently, distribution of this species was known from India (Arx et al. 1978; Arx 1985; Cannon 1986; Arx et al. 1988). Lately, S. thielavioides was isolated from biological soil crusts at the Mashash Farm in the Negev desert, Israel (Grishkan et al. 2006). Online database of the CABI Bioscience UK Centre Herbarium (IMI) includes record of Subramaniula sp. isolated from fruit of/associated with Capsicum from Pakistan in 1998 (IMI 379385, not seen). The finding of $S$. thielavioides on flower petals of Papaver somniferum from Slovakia represents the first record of the species in the country and the first known locality in Europe.

Acknowledgements. This study was supported by the Ministry of Agriculture of Slovak Republic, Grant No. 2006 UO 27/091 05 01/091 0511 and partially supported by Science and Technology Assistance Agency under the contract No. APVT-27-009904.

\section{REFERENCES}

Arx J. A. von 1985. On Achaetomium and a new genus Subramaniula (Ascomycota). Proc. Indian Acad. Sci. (Plant Sci.) 94 (2-3): 341-345.

Arx J. A. von, Figueras M. J., Guarro J. 1988. Sordariaceous ascomycetes without ascospore ejaculation. Beih. Nova Hedwigia 94: 1-104.

Arx J. A. von, Mukerji K. G., Singh N. 1978. A new coprophilous ascomycete from India. Persoonia 10 (1): 144-146.

Cannon P. F. 1986. A revision of Achaetomium, Achaetomiella and Subramaniula, and some similar species of Chaetomium. Trans. Br. Mycol. Soc. 87 (1): 45-76.

Grishkan I., Zaady E., Nevo E. 2006. Soil crust microfungi along a southward rainfall gradient in desert ecosystems. Eur. J. Soil Biol. 42 (1): 33-42.

Leslie J.F., Summerell B.A. 2006. The Fusarium laboratory manual. Blackwell publishing, Iowa, USA.

Lizoň P., Bacigálová K. 1998. Fungi. (In:) K. Marhold, F. Hindák (eds). Checklist of non-vascular and vascular plants of Slovakia. 1 ed., Veda, Bratislava: 101-227. 

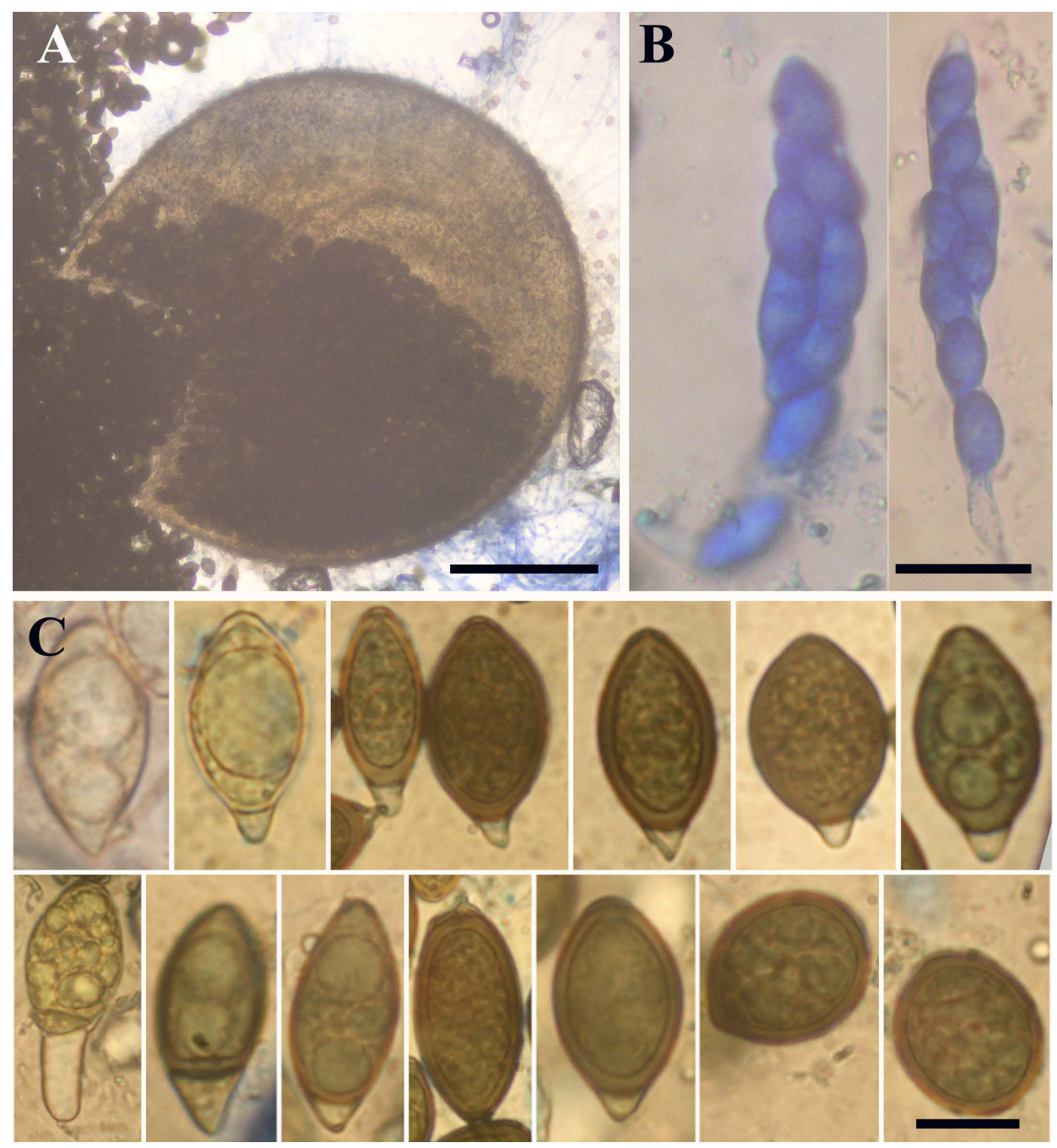

Fig. 1. Subramaniula thielavioides: A - globose ascoma, scale bar: $100 \mu \mathrm{m}$; B - asci with ascospores, scale bar: $20 \mu \mathrm{m}$; C - ascospores, scale bar: $15 \mu \mathrm{m}$. 